\title{
ANALISIS KUANTITATIF DAN KUALITATIF PENGENDALIAN BAHAYA TEMPAT KERJA DI PERUSAHAAN MACHINERY PT. X BEKASI
}

\author{
Wahyu Setia Wisesa, Ida Betanursanti \\ Program Studi Teknik Industri \\ Sekolah Tinggi Teknologi Muhammadiyah Kebumen \\ Jl. Indrakila 38 A Kebumen \\ wahyou.wiseza457@gmail.com
}

\begin{abstract}
Abstrak
Perusahaan wajib menerapkan keselamatan dan kesehatan kerja, tetapi bagaimana manajemen dan karyawan dalam mempraktekan pengendalian bahaya di tempat kerja perlu dilakukan pengkajian. Tujuan penelitian ini adalah untuk mencari pengaruh pengendalian bahaya di tempat kerja secara kuantitatif pada perusahaan machinery PT. X Bekasi.

Metode yang digunakan adalah kuesioner dan pengamatan lapangan dengan melibatkan 56 karyawan secara acak sebagai responden. Secara kuantitatif kuesioner diolah menggunakan uji statistik dengan SPSS versi 21 untuk mencari korelasi secara linier regresi sedangkan secara kualitatif pengamatan didokumentasikan berdasarkan kelengkapan penunjang pengendalian bahaya di tempat kerja.

Hasil yang diperoleh menunjukkan adanya korelasi secara linier antara pengendalian bahaya di tempat kerja $(Y)$, terhadap desain organisasi $\left(X_{1}\right)$, faktor pengendalian manusia $\left(X_{2}\right)$ dan pengendalian teknis $\left(X_{3}\right)$ dalam bentuk: $Y=-5,355+1,037 \cdot X_{1}+0,996 \cdot X_{2}+1,017 \cdot X_{3}$ dengan koefisien determinasi $\left(R^{2}\right)=$ 0,994 . Hasil pengamatan kualitatif di lapangan menunjukkan masih perlu peran aktif dari pihak manajemen perusahaan dan karyawan dalam menerapkan peraturan $K 3$ serta mengendalikan bahaya di tempat kerja.
\end{abstract}

Kata kunci : Pengendalian Bahaya, Desain Organisasi, Faktor Pengendalian Manusia, Pengendalian Teknis.

\section{PENDAHULUAN}

Produktivitas sumber daya manusia ditentukan oleh sejauh mana sistem yang ada di perusahaan mampu menunjang dan memuaskan keinginan seluruh pihak. Apabila suatu perusahaan peduli dengan keberadaan dan kesejahteraan karyawan, maka karyawan akan meningkatkan produktivitas kerjanya terhadap perusahaan. Salah satu faktor yang mempengaruhi produktivitas karyawan adalah pengendalian bahaya di tempat kerja pada sistem manajemen keselamatan dan kesehatan kerja (SMK3) yang merupakan aspekpenting dalam usaha meningkatkan serta produktivitas.Kecelakaan kerja tidak harus dilihat sebagai takdir, karena kecelakaan itu tidak terjadi begitu saja, kecelakaan pasti ada penyebabnya bisa dari kelalaian perusahaan yang semata-mata memusatkan diri pada keuntungan dan kelalaian karyawan yang mengabaikan peraturan, merupakan dua penyebab besar kematian terhadap pekerja.Apabila tingkat keselamatan kerja tinggi maka kecelakaan yang menyebabkan sakit, cacat dan kematian dapat ditekan sekecil mungkin. Apabila pengendalian bahaya di tempat kerja rendah, maka hal tersebut akan berpengaruh buruk terhadap keselamatan dan kesehatan tenaga kerja sehingga berakibat pada produktivitas yang menurun. Pengendalian bahaya di tempat kerja pada sistem manajemen keselamatan dan kesehatan kerja akan menciptakan terwujudnya pemeliharaan tenaga kerja yang baik. Apabila banyak terjadi kecelakaan, maka tenaga kerja banyak yang menderita, angka absensi di perusahaan meningkat, hasil produksi menurun dan biaya pengobatan semakin membesar. Ini semua akan menimbulkan kerugian bagi tenaga kerja maupun perusahaan yang bersangkutan, karena tenaga kerja terpaksa berhenti bekerja sebab sakit sementara atau cacat tetap yang diakibatkan oleh proses kerja yang tidak aman atau peralatan kerja yang salah dalam pengoperasiannya. Sebagaimana tujuan kerja adalah bukan semata hanya untuk menghasilkan upah kerja saja melainkan hakikatnya untuk menjaga kelangsungan hidup. Hal tersebut justru akan membawa dampak negatif terhadap 
efektifitas kerja. Tujuan perusahaan dan karyawan akan dapat selaras tercapai bila ditunjang dengan pengendalian bahaya di tempat kerja padasistem manajemen keselamatan dan kesehatan kerja.

Berdasarkan permasalahan yang ada pada latar belakang di atas, maka perumusan masalah yang akan dibahas pada penelitian ini adalah melakukan analisis secara kuantitatif besarnya pengaruh pengendalian teknis, faktor pengendalian manusia, dan desain organisasi terhadap pengendalian bahaya di tempat kerja dan pengamatan lapangan. Batasan masalah pada penelitian ini dengan mengolah kuesioner secara statistik dan linier regresi pada variabel-variabel penelitian menggunakan SPSS versi 21.Tujuan penelitian ini adalah melakukan pengamatan lapangan dan mencari besarnya pengaruh antara pengendalian teknis, faktor pengendalian manusia dan desain organisasi terhadap pengendalian bahaya di tempat kerja.

\section{LANDASAN TEORI}

\section{A. Kajian Pustaka}

Apabila keselamatan dan kesehatan kerja dilaksanakan dengan baik dan benar di industri yang sangat beresiko pada kesehatan karyawan, akan dapat meminimalisir cidera dan kecelakaan kerja. Penelitian yang dilakukan oleh (Mimala A., Zailina H., and Shamsul Bahari, S., 2004) terkait paparan pengerjaan timbal pada pekerja solder pabrik elektronik menyatakan bahwa ada perbedaan yang signifikan pada konsentrasi udara antara responden yang terpapar dan responden yang tidak terpapar. Konsentrasi serbuk timbal pada area permukaan sisi kanan secara signifikan lebih tinggi dari area permukaan sisi kiri. Namun, tidak ada perbedaan yang signifikan konsentrasi timbal dalam darah dan tekanan darah antara responden yang terpapar dan yang tidak terpapar, seperti konsentrasi serbuk timbal secara tidak langsung berkontribusi terhadap konsentrasi timbal dalam darah dan akhirnya timbal dalam darah pada tingkat bawah $10 \mathrm{ug} / \mathrm{dl}$, tidak menyebabkan peningkatan tekanan darah yang memicu terjadinya gangguan kesehatan bagi karyawan. Kesimpulannya,para pekerja solder di pabrik timah elektronik ini tidak beresiko tinggi terkena paparan timbal dari tempat kerja karena perusahaan sudah menerapkan sistem keselamatan dan kesehatan kerja dengan baik.

Bekerja di perusahaan pengerjaan logam perlu mempertimbangkan resiko macammacam bahan kimia yang dipergunakannya seperti aerosol.Batas paparan kerja fluida aerosol untuk karyawan pada industri pengerjaan logam dilaporkan oleh (Park, 2012).Ambang batas fluida aerosol occupational exposure limit (OEL) baik itu mineral atau minyak kimia yang dihasilkan dalam operasi pengerjaan logam, ukuran OEL yang tepat digunakan untuk mencegah berbagai resiko kesehatan yang mungkin berbeda antara fluida metalworking (MWF). Paparan jangka pendek OEL rata-rata tertimbang, $5 \mathrm{mg} / \mathrm{m}^{3}$ dan $15 \mathrm{mg} / \mathrm{m}^{3}$ diterapkan untuk MWF aerosol. Berdasarkan asumsi bahwa tidak ada perbedaan yang signifikan dalam resiko kesehatan di antara jenis cairan. Batas paparan yang direkomendasikan lembaga K3 untuk MWF aerosol $\left(0,5 \mathrm{mg} / \mathrm{m}^{3}\right)$ akan menjadi langkah efektif untuk meminimalkan dan mengevaluasi iritasi pernapasan bagian atas yang disebabkan oleh MWF murni atau yang dilarutkan. Bahaya akibat menghirup aerosol diantaranya asma dan pneumonitis hipersensitif disebabkan oleh kontaminan mikroba yang dihasilkan hanya dengan menggunakan cairan yang larut dalam air.

(Kim dkk., 2013) dalam penelitiannya pada pekerja pengecatan bemper mobil di Korea Selatan menyatakan bahwa pentingnya penggunaan dan pemilihan jenis masker ketika bekerja akan mempengaruhi resiko paparan bahan kimia karsinogenik berupa krom timbal yang terdapat pada cat utamanya yang berwarna kuning. Pengecatan dengan cat warna kuning meningkatkan konsentrasi kromium heksavalen pada udara sebanyak $118,33 \mu \mathrm{g} / \mathrm{m}^{3}$ dan analisis bahan cat dalam jumlah besar menunjukan bahwa kromium heksavalen banyak ditemukan pada bentuk krom timbal. Konsentrasi 
strontium kromat juga terdeteksi meningkat sejalan dengan tingkat kecerahan warna kuning. Beberapa cat terdapat sekitar $1 \%$ kristal silikon dalam bentuk kuarsa. Lamanya paparan terhadap bahan karsinogenik dalam cat berpengaruh pada stadium kanker penderita.

Penelitian (Halim, 2012) mengenai kelelahan otot yang dialami karyawan sepanjang bekerja dilakukan dengan berdiri selama minimal lima jam sehari dapat menyebabkan kelelahan baik secara fisik dan psikologis. Kelelahan psikologis yang dialami oleh para pekerja diperoleh melalui survei kuesioner. Karyawan yang bekerja sebagai metal stamping selama bekerja melibatkan interaksi otot-otot anggota gerak, sehingga kelelahan dapat diukur.Aktivitas otot telah dianalisis menggunakan pengukuran elektromiografi permukaan (sEMG). Kelelahan pertama terjadi pada right gastrocnemius muscleketika 20,2 menit dan terakhir pada menit ke-46 pada left gastrocnemius muscle. Sedangkan pada right tibialis anterior muscle kelelahan yang terjadi paling akhir dicatat dalam waktu 39.1 menit. Semua subjek melaporkan kelelahan pada satu atau lebih otot yang dinilai.Berdasarkan hasil, keluhan yang sangat kelelahan itu kritis dilaporkan pada otot gastrocnemius (kaki posterior).
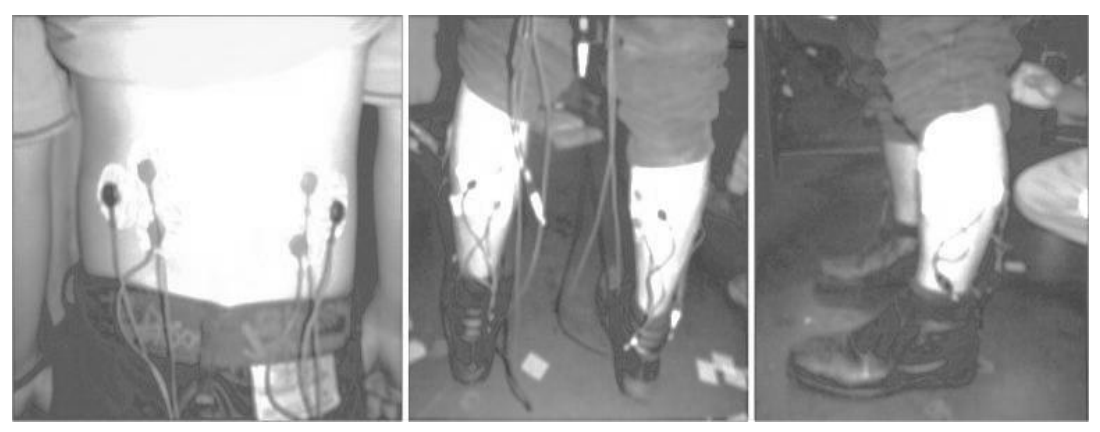

Gambar 1.Surface electrodes yang dipasang pada erector spinae muscles (lower back), gastrocnemius muscles (posterior legs) dan tibialis anterior muscles (anterior legs) (sumber : Halim, 2012)

\section{B. Pengendalian bahaya di tempat kerja}

Penelitian Menurut Smith, Carayon dan Karsh dalam Handbook of Industrial Engineering : Technology and Operations Management(Salvendy, 2001) menyatakan bahwa Ada dua konsep dalam pengendalian bahaya ditempat kerja, konsep yang pertama adalah pengendalian bahaya sebagai hirarki metode pengendalian. Pada hirarki ini metode pengendalian yang terbaik adalah membatasi bahaya melalui redesain dan substitusi, bila eliminasi atau substitusi tidak tercapai maka langkah pendekatan terbaik adalah pemblokiran akses karyawan terhadap bahaya. Bila pemblokiran karyawan tidak tercapai maka langkah terakhir memberikan peringatan kepada karyawan terhadap bahaya dan melatih mereka bagaimana untuk menghadapi bahaya. Konsep kedua dari pengendalian bahaya adalah mengklasifikasikan dalam 3 pengendalian bahaya yaitu: pengendalian teknis, faktor pengendalian manusia dan desain organisasi. Pengendalian teknis meliputi : modifikasi teknologi, stasiun kerja, peralatan, lingkungan, atau aspek fisik pekerjaan,untuk mengeliminasi, menghilangkan, menggantikan atau memblokir akses terhadap bahaya. Faktor pengendalian manusia berhubungan dengan kenyamanan aktifitas kerja terhadap kemampuan karyawan. Pengendalian organisasi meliputi perbaikan prosedur dan praktek kerja, penyediaan pelatihan, rotasi karyawan untuk mengurangi jumlah paparan, dan memberikan waktu istirahat untuk mengurangi dampak bahaya. 


\section{METODOLOGI PENELITIAN}

Metode yang dilakukan pada penelitian ini secara kuantitatif berdasarkan data yang diperoleh dari perusahaan machinery PT. X Bekasi dengan responden karyawan di lima departemen yang berbeda, yaitu : departemen kantor, departemen workshop, departemen presshop, departemen painting, dan departemen finishgood. Perusahaan machinery PT. X di Bekasi.

Populasi adalah wilayah generalisasi yang terdiri atas subjek atau objek yang mempunyai karakteristik tertentu yang ditetapkan oleh peneliti untuk dipelajari dan ditarik kesimpulan (Iskandar, 2013).Populasi dalam penelitian ini karyawan pada perusahaan machinery PT. X Bekasi.

Sampel merupakan bagian dari populasi yang menjadi sumber data dari penelitian pemilihan sampel dalam hal ini dilakukan secara acak yang melibatkan 56 karyawan.

\section{A. Variabel Penelitian}

Pada penelitian ini terdapat dua variabel, yakni variabel bebas dan variabel terikat.Variabel bebas (X) adalah variabel yang menjadi sebab perubahan dan akan mempengaruhi variabel terikat dalam pola hubungannya, variabel bebas pada penelitian ini meliputi tiga variabel, yakni :Pengendalian Teknis $\left(\mathrm{X}_{3}\right)$, Faktor Pengendalian Manusia $\left(\mathrm{X}_{2}\right)$, Desain Organisasi $\left(\mathrm{X}_{1}\right)$.Variabel terikat $(\mathrm{Y})$ adalah yang dipengaruhi oleh variabel bebas. Dalam penelitian ini variabel terikatnya pengendalian bahaya tempat kerja di perusahaan machinery PT. X Bekasi.

\section{B. Data yang digunakan}

Dalam penelitian ini menggunakan data kuesioner terhadap karyawan perusahaan machinery PT. X Bekasi dengan masalah yang sedang dibahas. Dalam kuesioner, responden mencantumkan nama pribadi, bagian, jenis kelamin, dan departemen. Kuesioner ini untuk masing-masing variabel terdiri dari 10 pertanyaan tentang desain organisasi, faktor pengendalian manusia, serta pengendalian teknis. Untuk keperluan analisis, kuesioner diolah dengan cara memberikan bobot penelitian dari setiap pertanyaan. Adapun skor jawabannya menggunakan skala Likert 5 sebagai berikut :Sangat Setuju (SS) bernilai 5, Setuju (S) bernilai 4, Tidak Dapat Menentukan (TDM)bernilai 3, Tidak Setuju (TS)bernilai 2, Sangat Tidak Setuju (STS) bernilai 1 untuk pertanyaan yang bersifat positif sehingga tidak ada pertanyaan bersifat negatif. Data kualitatif diambil berdasarkan pengamatan di lapangan dan dibandingkan dengan kelengkapan penunjang pengendalian bahaya di tempat kerja.

\section{Metode Pengumpulan Data}

Setelah pengambilan data dengan kuesioner selesai, kuesioner dihitung jumlah skornya dari masing-masing sampel karyawan perusahaan machinery PT. X Bekasi.Uji validitas dan reliabilitas dengan menghitung jumlah skor dari sampel berdasarkan pertanyaan kuesioner, kemudian data dimasukkan ke program SPSS (Statistical Product and Service Solutions) versi 21. Dari penyelesaian program SPSS versi 21 maka menghasilkan kesimpulan bahwa variabel penelitian tersebut dinyatakan valid dan reliabel atau tidak sama sekali. Selain itu dengan program SPSS digunakan untuk menghitung uji $\mathrm{T}$, uji $\mathrm{F}$ dan koefisien determinasi $\left(\mathrm{R}^{2}\right)$.Dokumentasi hasil pengamatan di lapangan dianalisis dan dibandingkan dengan kelengkapan penunjang pengendalian bahaya di tempat kerja. 


\section{Uji Validitas dan UjiReliabilitas} 2013).

Uji Validitas dan Uji Reliabilitas dapat dijabarkan sebagai berikut ini (Iskandar,

1. Uji validitas dilakukan untuk mengetahui apakah alat ukur (kuesioner) yang disusun benar-benar mampu mengukur atau menguji dengan valid dan diketahui kebenarannya. Pengujian validitas ini dilakukan melalui cara uji korelasi antara skor tiap-tiap variabel dengan skor total kuesioner kemudian diselesaikan menggunakan program SPSS versi 21.

2. Uji reliabilitas bertujuan untuk mengetahui apakah alat pengumpul data (kuesioner) menunjukkan tingkat ketepatan, keakuratan, kestabilan atau konsistensi. Dengan kata lain menunjukkan sejauh mana hasil pengukuran tetap konsisten jika dilakukan pengukuran dua kali atau lebih terhadap masalah yang sama. Nilai masing-masing variabelnya sama dengan uji validitas. Pengujian reliabilitas ini dilakukan dengan penyelesaian menggunakan program SPSS versi 21. Kriteria indeks reliabilitas (Santoso, 2001), adalah sebagai berikut :0,00 s/d 0,20kurang baik, > 0,20 s/d 0,40agak baik, > 0,40 s/d 0,60cukup baik, >0,60 s/d 0,80baik, > $0,80 \mathrm{~s} / \mathrm{d} 1.00$ sangat baik.

\section{E. Uji Hipotesis}

Uji hipotesis dalam penelitian ini menggunakan uji $\mathrm{T}$, uji $\mathrm{F}$ serta koefisien diterminasi $\left(\mathrm{R}^{2}\right)$ dengan uji dua arah dan tingkat signifikan $(\alpha)$ sebesar $5 \%$.

\section{Uji T}

Uji statistik $\mathrm{T}$ pada dasarnya menunjukkan seberapa jauh pengaruh satu variabel bebas secara individual dalam menerangkan variasi variabel terikat. Rumus yang digunakan untuk uji T dengan menggunakan program SPSS.

\section{Uji F}

Uji statistik F digunakan untuk menentukan apakah secara bersama-sama variabel terikat mampu menjelaskan variabel bebas dengan baik atau apakah variabel terikat mempunyai pengaruh yang signifikan terhadap variabel bebas. Rumus yang digunakan untuk uji $\mathrm{F}$ dengan menggunakan program SPSS.

\section{Koefisien Determinasi $\left(\mathbf{R}^{2}\right)$}

Koefisien determinasi $\left(\mathrm{R}^{2}\right)$ digunakan untuk mengetahui berapa persen variasi variabel bebas dapat dijelaskan oleh variasi variabel terikat.Jika nilai $\mathrm{R}^{2}$ mendekati 1 maka terdapat pengaruh yang sangat kuat dan jika mendekati nilai 0 berarti memiliki pengaruh yang lemah. Rumus yang digunakan untuk menguji hipotesis tersebut dengan menggunakan program SPSS.

\section{HASIL DAN PEMBAHASAN}

\section{A. Hasil Uji Kuantitatif}

Dari hasil pengumpulan data penelitian yang diperoleh melalui kuesioner pengendalian bahaya di tempat kerja karyawan perusahaan machinery PT. X Bekasi sejumlah 56 orang terdistribusi pada 5 departemen yang berbeda sebagaimana ditunjukkan pada gambar berikut: 


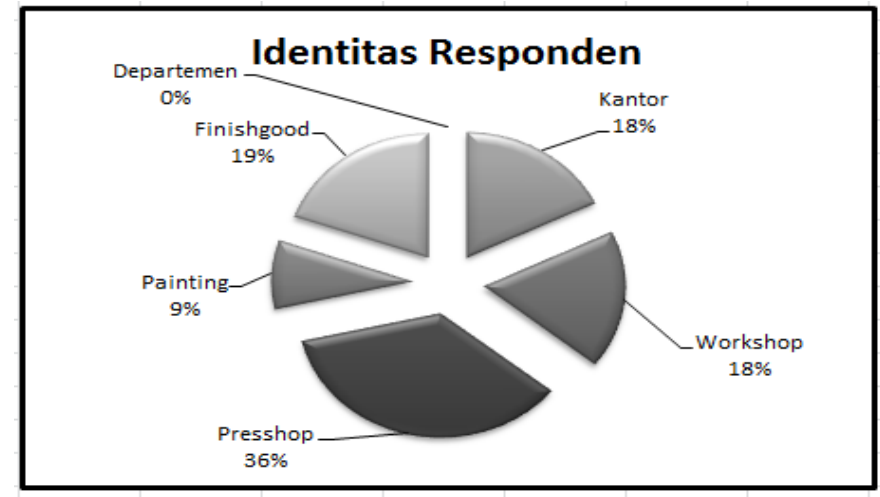

Gambar 2. Identitas Responden

Hasil skor kuesioner secara umum pada variabel yang diteliti di tunjukkan pada tabel 1 berikut ini.

Tabel 1. Hasil Skor Kuesioner

\begin{tabular}{lll}
\hline No. & Variabel & Skor \\
\hline 1 & Desain Organisasi $\left(\mathrm{X}_{1}\right)$ & 1761 \\
2 & Faktor Pengendalian Manusia $\left(\mathrm{X}_{2}\right)$ & 1684 \\
3 & Pengendalian Teknis $\left(\mathrm{X}_{3}\right)$ & 1662 \\
4 & Pengendalian Bahaya di tempat kerja $(\mathrm{Y})$ & 5141 \\
\hline
\end{tabular}

\section{B. Pembahasan}

Uji validitas item adalah uji statistik yang digunakan untuk menentukan seberapa valid suatu item pertanyaan dalam mengukur variabel yang diteliti dalam arti mampu memberikan hasil alur yang tepat dan akurat sesuai dengan maksud tes tersebut, uji reliabilitas item adalah uji statistik yang digunakan guna menentukan reliabilitas atau tingkat kepercayaan serangkaian item pertanyaan dalam kehandalannya mengukur suatu variabel. Variabel-variabel yang diteliti melalui kuesioner di perusahaan machinery PT. X Bekasi meliputi tiga aspek, yaitu : pengendalian teknis $\left(\mathrm{X}_{3}\right)$, faktor pengendalian manusia $\left(\mathrm{X}_{2}\right)$, desain organisasi $\left(\mathrm{X}_{1}\right)$.

1. Uji Validitas

Total jumlah nilai data dari masing-masing ke3 variabel di uji validitasnya menggunakan SPSS versi 21, kemudian diperoleh hasil data sebagai berikut ini.

Tabel 2. Hasil Uji Validitas

\begin{tabular}{|c|c|c|c|c|}
\hline \multicolumn{5}{|c|}{ Correlations } \\
\hline & & DESAIN & MANUSIA & TEKNIS \\
\hline \multirow[t]{3}{*}{ DESAIN } & Pearson Correlation & 1 & .509 & $.650^{x}$ \\
\hline & Sig. (2-tailed) & & .133 & .042 \\
\hline & $N$ & 10 & 10 & 10 \\
\hline \multirow[t]{3}{*}{ MANUSIA } & Pearson Correlation & .509 & 1 & .266 \\
\hline & Sig. (2-tailed) & .133 & & .457 \\
\hline & $N$ & 10 & 10 & 10 \\
\hline \multirow[t]{3}{*}{ TEKNIS } & Pearson Correlation & $650^{*}$ & .266 & 1 \\
\hline & Sig. (2-tailed) & .042 & .457 & \\
\hline & $N$ & 10 & 10 & 10 \\
\hline
\end{tabular}

Berdasarkan tabel 2 dapat dilihat bahwa masing-masing variabel memiliki korelasi Pearson lebih besar dari 0,25 oleh karenanya dapat dinyatakan bahwa data tersebut valid. Hasil korelasi Pearson pada desain organisasi bernilai 1 sedangkan pengendalian manusia bernilai 0,509 kemudian pengendalian teknis bernilai 0,650. Dari ketiga variabel yang dianalisis menunjukkan bahwa desain 
organisasi merupakan variabel yang paling signifikan.Dalam hal ini menurut penilaian para karyawan perusahaan sudah cukup berperan pada desain organisasi.Sedangkan faktor pengendalian manusia, pengendalian teknis menurut penilaian karyawan masih relatif kurang diperhatikan oleh pihak manajemen.

2. Uji Reliabilitas

Uji reliabilitas dilakukan dengan uji Alpha Cronbach dengan rumus sebagai berikut:

$$
\alpha=\left(\frac{K}{K-1}\right)\left(\frac{S_{r^{2}}-\sum S_{I^{2}}}{S_{X^{2}}}\right)
$$

Keterangan :

$\alpha=$ Koefisien reliabilitas Alpha Cronbach

$K=$ Jumlah item pertanyaan yang diuji

$\sum S_{t^{2}}=$ Jumlah varians skor item

$S X^{2}=$ Varians skor-skor tes (seluruh item $K$ )

Jika nilai alpha melebihi dari 0,7 artinya reliabilitas atau tingkat kepercayaan mencukupi. Hasil perhitungan uji reliabilitas menggunakan SPSS ditunjukkan pada tabel 3 berikut :

Tabel 3. Hasil Uji Reliabilitas

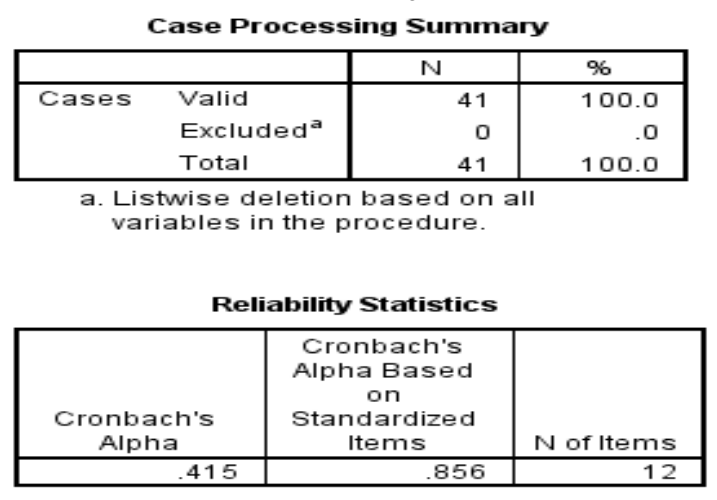

Dari tabel 3 di atas hasil reliabilitas menunjukkan bahwa Alpha Cronbach pada keseluruhan item bernilai 0,856 artinya secara umum data dapat dipercaya namun ada beberapa item yang nilainya rendah.

\section{Uji T}

Berdasarkan perhitungan SPSS dari ketiga variabel tersebut dinyatakansudah memenuhi standard, hal tersebut dapat dibuktikan dengan tabel berikut :

Tabel 4. Tabel Distribusi T

\begin{tabular}{|c|c|c|c|c|c|c|c|}
\hline Pr & 0.25 & 0.10 & 0.05 & 0.025 & 0.01 & 0.005 & 0.001 \\
\hline df & 0.50 & 0.20 & 0.10 & 0.050 & 0.02 & 0.010 & 0.002 \\
\hline 1 & 1.000 & 3.078 & 6.314 & 12.706 & 31.821 & 63.657 & 318.309 \\
\hline 2 & 0.816 & 1.886 & 2.920 & 4.303 & 6.965 & 9.925 & 22.327 \\
\hline 3 & 0.765 & 1.638 & 2.353 & 3.182 & 4.541 & 5.841 & 10.216 \\
\hline 4 & 0.741 & 1.533 & 2.132 & 2.776 & 3.747 & 4.604 & 7.173 \\
\hline 5 & 0.727 & 1.476 & 2.015 & 2.571 & 3.365 & 4.032 & 5.893 \\
\hline 6 & 0.718 & 1.440 & 1.943 & 2.447 & 3.143 & 3.707 & 5.208 \\
\hline 7 & 0.711 & 1.415 & 1.895 & 2.365 & 2.998 & 3.499 & 4.785 \\
\hline 8 & 0.706 & 1.397 & 1.860 & 2.306 & 2.896 & 3.355 & 4.501 \\
\hline . & . & . & - & - & - & . & . \\
\hline
\end{tabular}

Uji T digunakan untuk menguji perbedaan rata-rata dua kelompok yang saling berpasangan. Tabel di bawah menampilkan hasil uji beda rata-rata antara nilai variabel bebas dan variabel terikat. Hasil pengujian ditemukan bahwa nilai $\mathrm{T}$ 
sebesar -,315 dengan sig (2 tailed) 0,764. Hal ini menunjukkan bahwa ada perbedaan antara nilai variabel bebas dengan nilai variabel terikat dan oleh karena nilai $\mathrm{T}$ yang ditemukan negatif maka hal ini menunjukkan bahwa nilai variabel terikat lebih baik dari pada nilai variabel bebas.

Tabel 5. Hasil Uji T dengan SPSS

Coefficients $^{a}$

\begin{tabular}{|c|c|c|c|c|c|c|}
\hline \multirow{2}{*}{\multicolumn{2}{|c|}{ Model }} & \multicolumn{2}{|c|}{ Unstandardized Coefficients } & \multirow{2}{*}{$\begin{array}{c}\begin{array}{c}\text { Standardized } \\
\text { Coefficients }\end{array} \\
\text { Beta } \\
\end{array}$} & \multirow[b]{2}{*}{$\mathrm{t}$} & \multirow[b]{2}{*}{ Sig. } \\
\hline & & B & Std. Error & & & \\
\hline \multirow[t]{4}{*}{1} & (Constant) & $-5,355$ & 17,008 & &,- 315 & 764 \\
\hline & $\mathrm{X} 1$ & 1,037 &, 046 & ,925 & 22,341 &, 000 \\
\hline & $\mathrm{X} 2$ &, 996 &, 043 & 822 & 23,018 &, 000 \\
\hline & X3 & 1,017 &, 041 & ,902 & 24,639 &, 000 \\
\hline
\end{tabular}

a. Dependent Variable: $Y$

Dan terdapat perbedaan yang signifikan antara variabel berdasarkan perhitungan dari tabel 5. Terdapat korelasi yang linier antara $\mathrm{X}_{1}, \mathrm{X}_{2}$ dan $\mathrm{X}_{3}$ terhadap $\mathrm{Y}$. Dengan nilai $Y=-5,355+1,037 \cdot X_{1}+0,996 \cdot X_{2}+1,017 \cdot X_{3}$ artinya terdapat korelasi yang linier antara desain organisasi $\left(\mathrm{X}_{1}\right)$, faktor pengendalian manusia $\left(\mathrm{X}_{2}\right)$, pengendalian teknis $\left(\mathrm{X}_{3}\right)$ terhadap pengendalian bahaya ditempat kerja $(\mathrm{Y})$.

4. Uji F

Uji statistik F digunakan untuk menentukan apakah secara bersama-sama variabel terikat mampu menjelaskan variabel bebas dengan baik atau apakah variabel terikat mempunyai pengaruh yang signifikan terhadap variabel bebas. Berikut tabel uji F yang tersedia :

Tabel 6. Tabel Distribusi F

\begin{tabular}{|r|r|r|r|r|r|r|r|r|r|r|r|r}
\hline \multirow{2}{*}{$\begin{array}{c}\text { df untuk } \\
\text { penyebut } \\
\text { (fi2) }\end{array}$} & \multicolumn{10}{|c}{ df untuk pembilang (11) } \\
\hline & 1 & 2 & 3 & 4 & 5 & 6 & 7 & 8 & 9 & 10 & 11 & 12 \\
\hline 1 & 161 & 199 & 216 & 225 & 230 & 234 & 237 & 239 & 241 & 242 & 243 & 244 \\
2 & 18.51 & 19.00 & 19.16 & 19.25 & 19.30 & 19.33 & 19.35 & 19.37 & 19.38 & 19.40 & 19.40 & 19.41 \\
3 & 10.13 & 9.55 & 9.28 & 9.12 & 9.01 & 8.94 & 8.89 & 8.85 & 8.81 & 8.79 & 8.76 & 3.74 \\
4 & 7.71 & 6.94 & 6.59 & 6.39 & 6.26 & 6.16 & 6.09 & 6.04 & 6.00 & 5.96 & 5.94 & 5.91 \\
5 & 6.61 & 5.79 & 5.41 & 5.19 & 5.05 & 4.95 & 4.88 & 4.82 & 4.77 & 4.74 & 4.70 & 4.68 \\
6 & 5.99 & 5.14 & 4.76 & 4.53 & 4.39 & 4.28 & 4.21 & 4.15 & 4.10 & 4.06 & 4.03 & 4.00 \\
7 & 5.59 & 4.74 & 4.35 & 4.12 & 3.97 & 3.87 & 3.79 & 3.73 & 3.68 & 3.64 & 3.60 & 3.57
\end{tabular}

Berdasarkan pengolahan data dengan SPSS diperoleh data Uji F sebagai berikut ini.

Tabel 7. Hasil Uji F dengan SPSS versi 21

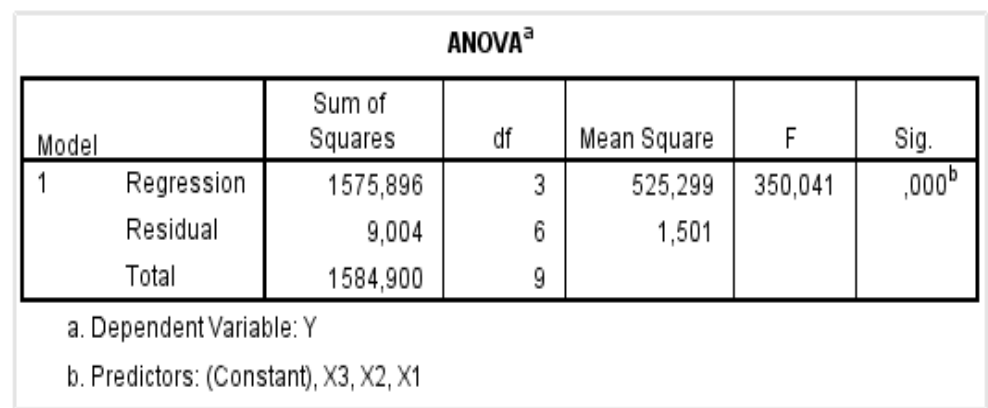


Bagian pada tabel 7 diatas menampilkan uji beda rata-rata secara keseluruhan. Pada tabel tersebut ditemukan harga $\mathrm{F}$ hitung sebesar 350,041 dengan sig = 0,000 . Oleh karena nilai sig $<0,05$ maka :

Ho : tidak ada pengaruh dari pengendalian teknis $\left(\mathrm{X}_{3}\right)$, faktor pengendalian manusia $\left(\mathrm{X}_{2}\right)$, desain organisasi $\left(\mathrm{X}_{1}\right)$ terhadap penerapan pengendalian bahaya di tempat kerja (Y).

$\mathrm{Ha}$ : ada pengaruh dari pengendalian teknis $\left(\mathrm{X}_{3}\right)$, faktor pengendalian manusia $\left(\mathrm{X}_{2}\right)$, desain organisasi $\left(\mathrm{X}_{1}\right)$ terhadap penerapan pengendalian bahaya di tempat kerja (Y).

Pernyataan Hipotesis mula-mula (Ho) ditolak dan Hipotesis akhir (Ha) diterima karena terdapat pengaruh dari pengendalian teknis $\left(\mathrm{X}_{3}\right)$, faktor pengendalian manusia $\left(\mathrm{X}_{2}\right)$, desain organisasi $\left(\mathrm{X}_{1}\right)$ terhadap penerapan pengendalian bahaya di tempat kerja (Y).

\section{Determinasi}

Koefisien determinasi $\left(\mathrm{R}^{2}\right)$ digunakan untuk mengetahui berapa persen variasi variabel bebas dapat dijelaskan oleh variasi variabel terikat.Jika nilai $R^{2}$ mendekati 1 maka terdapat pengaruh yang sangat kuat dan jika mendekati nilai 0 berarti memiliki pengaruh yang lemah.Rumus yang digunakan untuk menguji hipotesis tersebut dengan menggunakan program SPSS versi 21. Dari hasil perhitungan diperoleh nilai determinasi $\mathrm{R}^{2}=0$, 994 yang berarti pengaruh variabel-variabel bebas desain organisasi $\left(\mathrm{X}_{1}\right)$, faktor pengendalian manusia $\left(\mathrm{X}_{2}\right)$, pengendalian teknis $\left(\mathrm{X}_{3}\right)$ berkorelasi linier terhadap variabel terikat pengendalian bahaya di tempat kerja (Y).

\section{Uji Linier Regresi}

Berdasarkan perhitungan diperoleh korelasi yang linier antara pengendalian bahaya di tempat kerja $(\mathrm{Y})$ dengan desain organisasi $\left(\mathrm{X}_{1}\right)$, faktor pengendalian manusia $\left(\mathrm{X}_{2}\right)$, pengendalian teknis $\left(\mathrm{X}_{3}\right)$, yang ditunjukkan dengan persamaan berikut ini :

$Y=-5,355+1,037 . X_{1}+0,996 . X_{2}+1,017 \cdot X_{3}$ dengan $R^{2}=0,994$

Dari persamaan diatas terbukti bahwa terdapat korelasi yang linier antar variabel dengan batasan $0<R^{2}<1$ nilai $R^{2}$ diperoleh $=0,994$. Terbukti bahwa masingmasing variabel bebas $\left(\mathrm{X}_{1}, \mathrm{X}_{2}, \mathrm{X}_{3}\right)$ berkorelasi secara linier antar variabel.

\section{Hasil Uji Kualitatif}

Berdasarkan hasil pengamatan lapangan, resiko yang terjadi dari kelima departemen di perusahaan machinery PT. X Bekasi adalah sebagai berikut :

\section{a. Departemen Kantor}

Kantor Perusahaan Machinery PT. X Bekasi yang berlantai 3 memiliki fasilitas yang memadai, hal tersebut dapat dilihat dari masing-masing ruangan, namun semua itu tidak menjamin bahwa tidak ada resiko akan terjadinya kecelakaan kerja. Seperti tangga, tangga di kantor sering menjadi kendala para karyawan yang naik dan turun. Lantai tangga licin karena dibangun dari keramik lantai biasa serta jarak anak tangga yang kurang ergonomis membuat kesulitan para karyawan yang melewatinya.Resiko yang bisa terjadi pada tangga seperti ini adalah terpeleset, terjatuh hingga terbentur. Selain tangga yaitu jarak monitor PC dengan tempat duduk yang terlalu dekat, juga berpengaruh buruk terhadap penglihatan, serta terdapat sudut pandang mata dengan monitor yang dilakukan secara lama sehingga menyebabkan kram pada leher dan punggung. Tempat duduk juga termasuk kendala dan resiko terjadinya kecelakaan kerja sehingga karyawan kerap mengalami kesemutan selain itu, meja kerja juga kurang nyaman untuk para staf karyawan dikantor. Resiko tersebut dapat diperbaiki dengan alat yang seharusnya dipakai adalah sebagai berikut : 
Tabel 8. Alat yang disarankan berserta fungsinya untuk Kantor

\begin{tabular}{cc}
\hline Alat & Fungsi \\
\hline Lantai tangga diberi step nosing & $\begin{array}{c}\text { Untuk pengaman anak tangga agar tidak } \\
\text { licin }\end{array}$ \\
Kursi Putar & Untuk menghindari kelelahan pada \\
& punggung, kaki serta tulang belakang \\
Meja Kantor & Meja kantor harus memiliki ruang yang \\
& cukup untuk menempatkan komputer dan \\
& sarana kerja tulis lainnya.
\end{tabular}

\section{b. Departemen Workshop}

Pada departemen workshop kerap kali dijumpai kecelakaan kerja seperti tangan tergores gerinda, mata merah terkena sinar cahaya las dan debu, serta batuk akibat menghirup udara yang kotor.Dari semua dampak kecelakaan kerja yang terjadi dapat dilihat karena kurangnya kesadaran penggunaan alat pelindung diri (APD) oleh karyawan.

Dalam hal ini karyawan masih kurang kesadarannya akan pentingnya dan kegunaan dari APD tersebut. Alat pelindung diri pada karyawan yang seharusnya dipakai adalah seperti pada tabel berikut :

Tabel 9. Alat yang disarankan berserta fungsinya untuk Departemen Workshop

\begin{tabular}{ll}
\hline Alat & Fungsi \\
\hline Sarung tangan & $\begin{array}{l}\text { Untuk melindungi tangan dari benda-benda keras dan } \\
\text { tajam. }\end{array}$ \\
Masker & Pelindung bagi pernafasan dari berbagai bentuk polusi. \\
Kacamata & $\begin{array}{l}\text { Kacamata pengaman digunakan untuk melindungi mata } \\
\text { dari serbuk debu, batu atau serpih besi yang ditiup } \\
\text { angin. }\end{array}$ \\
\hline
\end{tabular}

\section{c. Departemen Presshop}

Departemen presshop merupakan departemen yang paling banyak jumlah karyawan, sebab pada departemen ini terbagi atas tiga ruangan yakni dies, gudang dan presshop itu sendiri. Resiko yang terjadi pada departemen presshop ialah kurangnya ventilasi udara sehingga para karyawan kerap kali merasa gerah dan kepanasan lalu pencahayaan yang masih minim sehingga menyebabkan karyawan tidak teliti dalam pekerjaannya selain itu kebisingan dari alat-alat serta mesinmesin menjadi faktor yang sangat penting diperhatikan sehingga tidak menyebabkan sakit pada telinga.

Alat pelindung diri yang seharusnya juga digunakan oleh para karyawan Presshop adalah sebagai berikut : 
Tabel 10. Alat yang disarankan beserta fungsinya untuk Departemen Presshop

\begin{tabular}{ll}
\hline Alat & Fungsi \\
\hline Jendela & $\begin{array}{l}\text { Untuk menetralisir udara dalam ruangan sehingga tidak } \\
\text { menyebabkan pengap. }\end{array}$ \\
Penutup Telinga & $\begin{array}{l}\text { Alat ini digunakan untuk melindungi telinga dari bunyi } \\
\text { mesin presshop yang cukup keras dan bising. }\end{array}$ \\
Lampu & $\begin{array}{l}\text { Untuk pencahayaan sehingga di ruangan terang dan } \\
\text { nyaman bekerja bagi karyawan. }\end{array}$ \\
\hline
\end{tabular}

\section{d. Departemen Painting}

Painting merupakan departemen yang paling sedikit jumlah karyawan karena pada departemen ini adalah proses pewarnaan pada barang produksi menggunakan cairan kimia sehingga hanya karyawan yang memang ahli dalam bidang ini, khusunya pada bidang bahan kimia. Resiko yang terjadi pada departemen ini ialah lantai basah sehingga licin, jarak antara kompresor dengan larutan cairan kimia yang terlalu dekat sehingga menyebabkan pemicu terjadinya kebakaran dan keracunan serta kebersihan perlu diperhatikan karena bekerja dengan bahan-bahan yang berbahaya agar tidak mengenai tubuh.Karena bekerja dengan alat kimia sehingga karyawan memerlukan alat pelindung diri sebagai berikut ini.

Tabel 11. Alat yang disarankan beserta fungsinya untuk Departemen Painting

\begin{tabular}{ll}
\hline Alat & Fungsi \\
\hline Sarung tangan & $\begin{array}{l}\text { Untuk melindungi tangan dari bahan kimia } \\
\text { berbahaya dan meminimalisir kecelakaan kerja. }\end{array}$ \\
Sepatu Boot & $\begin{array}{l}\text { Sebagai alat pengaman pada kaki saat bekerja } \\
\text { ditempat yang becek atau basah }\end{array}$ \\
Baju Pelindung & $\begin{array}{l}\text { Untuk melindungi anggota tubuh dari goresan, panas } \\
\text { dan meminimalisir kecelakaan kerja. }\end{array}$
\end{tabular}

\section{e. Departemen Finishgood}

Proses akhir pada perusahaan Machinery PT. X Bekasi sebelum barang atau produk didistribusikan ke konsumen adalah di departemen finishgood. Resiko kecelakaan kerja yang terjadi pada departemen ini ialah barang maupun produk yang masih belum tertata rapi maupun berserakan dilantai dapat menyebabkan tertusuk pada kaki juga menyebabkan tergelincir.

Alat maupun pelindung diri yang seharusnya ada serta digunakan oleh perusahaan dan karyawan adalah sebagai berikut ini. 
Tabel 12. Alat yang disarankan beserta fungsinya untuk Departemen Finishgood

\begin{tabular}{ll}
\hline Alat & Fungsi \\
\hline Rak Tempat Sparepart & $\begin{array}{l}\text { Untuk tempat barang maupun produk sebelum di } \\
\text { packing agar tidak berserakan. }\end{array}$ \\
Sepatu Safety & $\begin{array}{l}\text { Untuk melindungi kaki dari bahaya tertusuk maupun } \\
\text { terbentur. }\end{array}$ \\
Troli Barang & $\begin{array}{l}\text { Untuk alat angkut barang agar tidak memerlukan } \\
\text { tenaga yang berlebihan }\end{array}$
\end{tabular}

\section{KESIMPULAN DAN SARAN}

\section{A. Kesimpulan}

Berdasarkan pengolahan data secara statistik pada perusahaan machinery PT. X Bekasi. Secara Kuantitatif menunjukkan korelasi linier yang signifikan antara desain organisasi $\left(\mathrm{X}_{1}\right)$, faktor pengendalian manusia $\left(\mathrm{X}_{2}\right)$, pengendalian teknis $\left(\mathrm{X}_{3}\right)$ terhadap pengendalian bahaya di tempat kerja $(\mathrm{Y})$ yang dinyatakan oleh persamaan $\mathrm{Y}=-5,355$ $+1,037 . X_{1}+0,996 \cdot X_{2}+1,017 . X_{3}$ dengan koefisien determinasi $R^{2}=0,994$.

Hasil pengamatan kualitatif di lapangan menunjukkan masih perlu peran aktif dari pihak manajemen perusahaan dan karyawan dalam menerapkan peraturan $\mathrm{K} 3$ dan mengendalikan bahaya di tempat kerja.

B. Saran

Perlu adanya penerapan tindak kedisiplinan serta sanksi yang tegas oleh pihak perusahaan kepada karyawannya yang tidak mematuhi aturan penggunaan APD pada saat bekerja.

Untuk karyawan lebih meningkatkan kewaspadaan dan mengikuti prosedur kerja yang berlaku di perusahaan, sebelum bekerja, saat bekerja, dan setelah bekerja.

\section{DAFTAR PUSTAKA}

[1] A, Mimala., Zailina H. dan Shamsul Bahari S., 2004, Occupational Lead Exposure of Soldering Workers in an Electronic Factory, Journal of Occupational Safety and Health Vol. 1, No. 2.

[2] Bella, Ukhisia GU,dkk. ,2013, Analisis Pengaruh Keselamatan dan Kesehatan Kerja terhadap Produktivitas Karyawan dengan MetodePartial Least Squares,Skripsi, Teknologi Industri Pertanian Universitas Brawijaya. http://skripsitip.staff.ub.ac.id/ files/2013/08/Jurnal-Bella-G-U.pdf (diakses 4 Maret 2015).

[3] Betanursanti, 2009, Pedoman Penulisan Skripsi \& Artikel Ilmiah, Sekolah Tinggi Teknologi Muhammadiyah Kebumen, Kebumen.

[4] Kim, Boowook, Y Jin-Ha dan Byung-Soon Choi, 2013, Exposure Assessment Suggests Exposure to Lung Cancer Carcinogens in a Painter Working in an Automobile Bumper Shop,Journal Safety and Health at Work, Vol. 3, No. 1.

[5] Park, Donguk, 2012,The Occupational Exposure Limit for Fluid Aerol Generated in Metalworking Operations: Limitations and Recommendations, Journal Safety and Health at Work, Vol. 3, No. 1.

[6] Halim, Isa,dkk., 2012, Assessment of Muscle Fatigue Associated with Prolonged Standing in the Workplace,Journal Safety and Health at Work Vol. 3, No. 1.

[7] Iskandar, D., 2013, Pengaruh Motivasi Karyawan Terhadap Produktivitas Perusahaan Tekstil PT. Unggulrejo Wasono di Purworejo, Skripsi, Teknik Industri Sekolah Tinggi Teknologi Muhammadiyah, Kebumen.

[8] Jian Liu, Z Xiaoyue dan Thurmon E. Lockhart, 2012, Fall Risk Assessment Based on Postural and Dynamic Stability Using Inertial Measurement Unit,Journal Safety and Health at Work, Vol. 3, No. 1. 
[9] Muhson, Ali, 2012, Pelatihan Analisis Statistik dengan SPSS, Fakultas Ekonomi Universitas Negeri Yogyakarta.

[10] Santoso, S., 2001, Bab VII. Analisis Regresi Linier Uji Validitas Dan Uji Reabilitas, http://ssantoso.umpo.ac.id/wp-content/uploads/ (diakses 11 Maret 2015).

[11] Smith, M.J., Carayon, P., dan Karsh, B., 2001, Desain for Occupational Health and Safety, in Salvendy, G., Handbook of Industrial Engineering : Technology and Operations Management,John Wiley and Sons, inc., New York.

[12] Wiseza Wahyu, 2014, Laporan Kerja Praktek Keselamatan dan Kesehatan Kerja (K3) Di PT. Hadeka Primantara, Sekolah Tinggi Teknologi Muhammadiyah Kebumen, Kebumen. 
